\title{
Values of apoptosis of lymphocytes and granulocytes in peripheral blood of Polish mixed-breed rabbits in the annual cycle
} \author{
A. Trzeciak-Ryczek ${ }^{1}$, W. Deptula ${ }^{2}$ \\ ${ }^{1}$ Department of Immunology, Faculty of Biology, \\ University of Szczecin, Z. Felczaka 3c, 71-412 Szczecin, Poland \\ ${ }^{2}$ Department of Microbiology, Faculty of Biology, \\ University of Szczecin, Z. Felczaka 3c, 71-412 Szczecin, Poland
}

B. Tokarz-Deptuła1, B. Hukowska-Szematowicz ${ }^{1}$, P. Niedźwiedzka-Rystwej ${ }^{1}$,

\begin{abstract}
The objective of the study was to determine values of apoptosis for peripheral blood lymphocytes and granulocytes, including dependency on the season of the year, in Polish mixed-breed rabbits and in mixed-breed rabbits with the addition of blood of meat-breed rabbits. The study was carried out in four seasons of the year (spring, summer, autumn, winter) involving 120 Polish mixed-breed rabbits - group I, and 120 Polish mixed-breed rabbits with addition of meat-breed rabbit blood - group II. Assessment of apoptosis of lymphocytes and granulocytes was performed using as FACScan cytometer by Becton Dickinson with FACSDiva software (USA), using as ApoFluor ${ }^{\circledR}$ Green Caspase reagent kit (MP Biomedicals, USA) to detect the activity of the total caspase pool 1, 3, 4, 5, 6, 7, 8, 9 in granulocytes and lymphocytes of rabbit peripheral blood. The results for apoptosis of lymphocytes and granulocytes in peripheral blood in the animals investigated (group I and II) were subjected to statistical analysis with the t'Student test at $\mathrm{p}=0.05$. It was noted that, in rabbits from group I, the values for apoptosis of lymphocytes were the highest in winter and autumn $(36.02 \%$ and $31.24 \%$, respectively), and the lowest in spring and summer $(26.73 \%$ and $22.72 \%$, respectively), whereas in the case of granulocytes the highest values were in summer and spring $(14.69 \%$ and $12.95 \%$, respectively), and the lowest in winter and autumn (8.16\% and $8.57 \%$, respectively). In mixed-breed rabbits with the addition of meat-breed blood (group II), the values for apoptosis of lympocytes were the highest in spring (29.13\%), and the lowest in summer $(25.43 \%)$; whereas in the case of granulocytes the highest values were in summer and spring (14.0\% and $11.15 \%$, respectively), and the lowest in autumn and winter (7.46\% and $7.64 \%$, respectively).
\end{abstract}

Key words: rabbits, apoptosis, Polish mixed-breed rabbits, annual cycle

Correspondence to: B. Tokarz-Deptuła, e-mail: kuki001@interia.pl, tel.: +48914441610 


\section{Introduction}

Among important properties of macro-organisms, there is the periodic nature of many of their life-cycles related, among others, to rhythms resulting from the seasons of the year, monthly and daily rhythms, as well as rhythms resulting from times of the day (Pyza and Nowak 1999, Bell-Pedersen at al. 2005, Takahashi et al. 2008, Casanova-Acebes at al. 2013, Gamble et al. 2014). According to Bell-Pedersen (Bell-Pedersen 2000), all levels of cellular processes in the macro-organism, including biochemical and behavioural, occur at shorter or longer intervals. Periodicity involves changes to such fundamental physiological processes in humans and vertebrates, as the metabolism, manifesting as a change in the body internal temperature (Bell-Pedersen at al. 2005), or hormone level (Gamble et al. 2014), as well as changes to biochemical factors (Deptuła and Dorynek 1993, Bell-Pedersen 2000, Zapata and al. 2003, Cetin et al. 2009), haematological factors (Jacobson et al. 1978, Deptuła et al. 1992, Deptuła and Dorynek 1993, Zapata et al. 2003, Nowaczyk et al. 2005, Cetin and al. 2009, Tokarz-Deptuła et al. 2014, Dopico et al. 2015, Husakova et al. 2015) and immunological factors (Deptuła et al. 1992, Nowaczyk et al. 2005, Hukowska-Szematowicz et al. 2015, Dopico et al. 2015, Tokarz-Deptuła et al. 2015), including immune system cells (Deptuła et al. 1992, Nowczyk et al. 2005, Casanova-Acebes 2013, De Jong et al. 2014, Dopico et al. 2015), the number of which is conditioned by programmed death - apoptosis.

Apoptosis refers to many cells of the macro-organism, and occurs both in physiological and pathological conditions, and it is now assumed to be an important element of immunity of mammals (Niedźwiedzka-Rystwej and Deptuła 2012, Niedźwiedzka-Rystwej and Deptuła 2012a, Niedźwiedzka-Rystwej et al. 2013, Niedźwiedzka-Rystwej et al. 2013a). Its role in immunology is related to, among others, immune system cells, which, after performing their function, are thus eliminated as damaged or changed cells (Baś et al. 2004, Elmore 2007, Niedźwiedzka-Rystwej and Deptuła 2012, Niedźwiedzka-Rystwej et al. 2013, Niedźwiedzka-Rystwej et al. 2013a). The facts place apoptosis of immune system cells at the focus of interest among immunologists, including diagnostics specialists. It has been shown that apoptosis of peripheral blood lymphocytes and granulocytes is a good prognostic factor used to assess immunity of the macro-organism (Weinmann et al. 2003, Stark et al. 2005), including in viral infections in humans with such viruses as EBV, HBV, HCV, HCMV, HPV and HSV (Solary et al. 1996, O'Brien 1998, Fadeel et al. 1999), as well as in rabbits infected with RHDV (Alonso et al. 1998, Niedźwiedzka and Deptuła 2012,
Niedźwiedzka and Deptuła 2012a, Hukowska-Szematowicz 2013, Niedźwiedzka at al. 2013, Niedźwiedzka et al. 2013a).

Despite rabbits being laboratory animals generally used in experimental and diagnostic studies, the literature lacks studies on physiological values for apoptosis of peripheral blood lymphocytes and granulocytes in such animals, including the assessment of this phenomenon depending on the periodicity of the seasons. This study was undertaken since rabbits are bred for meat and fur, and hence are economically important in Poland.

It has been shown, that in rabbits the season affects the quantity (Jacobson et al. 1978, Nowaczyk at al. 2005, Cetin at al. 2009) and activity (Nowaczyk et al. 2005, Hukowska-Szematowicz et al. 2015) of lymphocytes and granulocytes, and the quantity of monocytes (Jacobson et al. 1978, Nowczyk et al. 2005, Cetin et al. 2009) in peripheral blood, and thus these cells are subject to apoptosis. Such an interdependency was also observed in farm animals (cattle), where the impact of the season was recorded in respect of immune system cells (Deptuła et al. 1992, Deptuła and Dorynek 1993) and their activity (Deptuła et al. 1992, Deptuła and Dorynek 1993) in phagocytosis, and in the quantity of serum immunoglobulins and total protein; a slight seasonal impact was also reported in respect of the quantity of lymphocytes, granulocytes and monocytes in biungulates from the camelid family, including alpaca (Husakova at al. 2015) and guanaco (Zapata et al. 2003) and, in the case of the latter, also in respect of total protein volume (Zapata et al. 2003).

Analysis of such dependencies in the case of Polish mixed-breed rabbits, has indicated that periodicity related to the seasons affects the quantities of lymphocytes, neutrophil granulocytes, and acidophil granulocytes, as well as monocytes in peripheral blood, and the neutrophil phagocytosis process (Nowczyk et al. 2005). The correlation in such animals was reported in the form of higher values of lymphocyte and neutrophil granulocyte quantities in spring, as compared to summer and autumn (Nowczyk et al. 2005); and in the case of acidophil granulocytes in spring, as compared to summer and winter, summer compared to autumn, and autumn compared to winter (Nowaczyk et al. 2005). In respect of monocytes in such rabbits, higher values were observed in spring as compared to summer, and in summer as compared to autumn. Analogical observations in Angora rabbits (Cetin at al. 2009) referred just to the quantity of monocytes, since higher values in such cells were only obtained in winter, as compared to summer. In "cottontail" type rabbits (Jacobson et al. 1978), the impact of the seasons on the quantity of peripheral blood elements was high, since higher values of neutrophil 
granulocytes were observed in such animals in summer as compared to autumn, and in winter and spring as compared to summer. In the case of acidophil granulocytes in such animals, higher values were observed in summer, as compared to autumn and winter (Jacobson et al. 1978).

Analysis of the impact of the seasons, however, on the activity of peripheral blood leucocytes in rabbits, indicates that the season affects one of the phases of phagocytosis - adherence capacity: higher values of this parameter were recorded in such animals in spring, as compared to summer and winter, and in summer, as compared to winter (Nowczyk et al. 2005): Analogical correlation was observed in such animals in the quantity of serum immunoglobulins ( $\mathrm{Ig}$ ) defined in ZST units (Nowczyk et al. 2005): they were higher in spring and summer, as compared to winter. The results were also confirmed in other studies (Hukowska-Szematowicz et al. 2015), where higher values of serum Ig were found in summer, as compared to winter. The impact of the season of the year was also recorded in such animals in respect of concentration of serum immunoglobulins $G$ (Hukowska-Szematowicz et al. 2015) in summer, as compared to winter, and in spring compared to summer.

In biungulate mammals from the camelid family guanaco (Zapata et al. 2003), however, an increase in total protein volume was observed in winter, as compared to other seasons of the year. In the case of the quantity of immune system cells - lymphocytes, granulocytes and monocytes (Zapata et al. 2003) - the same study indicated that the season only slightly affects the quantity of such cells, and the impact was not statistically significant. Very similar results to the results obtained for guanaco (Zapata et al. 2003) in respect of the quantity of lymphocytes, granulocytes and monocytes were obtained for mammals from the camelid family - alpaca (Husakova et al. 2015), where a slight impact of the season was also observed in respect of the quantity of such cells.

The image obtained of the impact of the seasons on the quantity of lymphocytes, granulocytes and monocytes, and immunological activity of peripheral blood granulocytes and lymphocytes in rabbits (Jacobson et al. 1978, Nowczyk et al. 2005, Cetin et al. 2009, Hukowska-Szematowicz et al. 2015), farm animals (Deptuła et al. 1992, Deptuła and Dorynek 1993) and biungulate mammals from the camelid family (Zapata et al. 2003, Husakova et al. 2015), was also confirmed in humans, where impact of the season has found on the quantity of lymphocytes, monocytes, platelets, and erythrocytes (Dopico et al. 2015), and on genes conditioning synthesis of IL-6 and acute-phase proteins (CRP) (Dopico et al. 2015). Such observations were confirmed by De Jong et al. (2014) in humans; their study showed that the seasons also affect gene expression, conditioning the quantity of granulocytes, lymphocytes, and monocytes in peripheral blood. According to Bell-Pedersen (2000), the periodicity clock in mammals, including humans, is omnipresent, since it affects to many processes and operates on all levels of biochemical processes in cells and tissues, while in humans it additionally affects, among others, endocrinological functions, including sleep cycles, and conditions the course of mental diseases and drug tolerance. According to Casanova-Acebes et al. (2013), the phenomenon of periodicity also includes the process of haematopoiesis, in particular granulocyte cells, as well as (Gamble et al. 2014) the release of such hormones as melatonin, growth hormones, adiponectin, and insulin.

\section{Aim of the study}

Since there is a correlation in humans and animals, including rabbits, between the quantity of immune system cells in peripheral blood and their immunological activity on the one hand, and periodicity related to the seasons on the other, the aim of this study was to determine values of apoptosis for peripheral blood lymphocytes and granulocytes, including dependence on the season of the year, in Polish mixed-breed rabbits and in mixed-breed rabbits with an addition of blood of meat-breed rabbits.

\section{Materials and Methods}

The study was carried out in four seasons of the year (spring, summer, autumn, winter) and involved 240 Polish mixed-breed rabbits, including 120 Polish mixed-breed rabbits - group I, and 120 Polish mixed-breed rabbits with addition of meat-breed rabbit blood - group II, weighing 3.2-4.2 kg, aged 3-6 months, males and females labelled as conventional animals, originating from a licenced farm under complete zoo-technical and veterinary supervision (Anon 1987). The average age of each group of animals in the four seasons was very similar, and amounted to 4.5-5 months. The ratio of females to males in our study groups, was close to $1: 1$; the animal number in each group, numbering 30 animals in each season, was as follows: the first group - spring (13 females and 17 males), the second group- summer (14 females and 16 males), the third group- autumn (17 females and 13 males), the fourth group- winter (14 females and 16 males). During the study, the rabbits remained at the vivarium of the Department of Microbiology and Department of Immunology at the Faculty of Biology, 
Table 1. Values for apoptosis of peripheral blood lymphocytes and granulocytes in Polish mixed-breed rabbits in annual cycle (group I).

\begin{tabular}{cccccc}
\hline \multirow{2}{*}{ Parameters analysed } & \multicolumn{5}{c}{ Parameter values in particular seasons of the year } \\
\cline { 2 - 6 } & & spring (May) & summer (June) & autumn (October) & winter (January) \\
\cline { 2 - 6 } & & $(30)$ & $(30)$ & $(30)$ & $(30)$ \\
\hline Percentage of apoptotic & $\bar{x}$ & 26.73 & 22.72 & $31.24^{4}$ & $36.02^{3.5}$ \\
lymphocytes & $\mathrm{SD} \pm$ & 5.76 & 4.44 & 8.79 & 8.99 \\
\hline Percentage of apoptotic & $\bar{x}$ & $12.95^{2.3}$ & $14.69^{4.5}$ & 2.05 & 2.16 \\
granulocytes & $\mathrm{SD} \pm$ & 2.59 & 3.42 & & 2.92 \\
\hline
\end{tabular}

Legend: numbers in parentheses indicate number of rabbits; $\bar{x}$ - average value; SD \pm - standard deviation; statistically significant difference between: 1 - spring and summer, 2 - spring and autumn, 3 - spring and winter, 4 - summer and autumn, 5 - summer and winter, 6 - autumn and winter

Table 2. Values for apoptosis of peripheral blood lymphocytes and granulocytes in Polish mixed-breed rabbits with addition of meat-breed rabbits blood in annual cycle (group II).

\begin{tabular}{cccccc}
\hline \multirow{2}{*}{ Parameters analysed } & \multicolumn{5}{c}{ Parameter values in particular seasons of the year } \\
\cline { 3 - 6 } & & spring (May) & summer (June) & autumn (October) & winter (January) \\
\cline { 2 - 6 } & & $(30)$ & $(30)$ & $(30)$ & $(30)$ \\
\hline Percentage of apoptotic & $\bar{x}$ & 29.13 & 25.43 & 26.04 & 28.86 \\
lymphocytes & $\mathrm{SD} \pm$ & 6.04 & 5.79 & 7.19 & 7.67 \\
\hline Percentage of apoptotic & $\bar{x}$ & $11.15^{2.3}$ & $14.20^{4.5}$ & 3.64 \\
granulocytes & $\mathrm{SD} \pm$ & 3.21 & 3.29 & 3.82 & 3.63 \\
\hline
\end{tabular}

Legend: numbers in parentheses indicate number of rabbits; $\bar{x}$ - average value; SD \pm - standard deviation; statistically significant difference between: 1 - spring and summer, 2 - spring and autumn, 3 - spring and winter, 4 - summer and autumn, 5 - summer and winter, 6 - autumn and winter

University of Szczecin, where the conditions of the rooms regarding temperature, humidity and lighting conformed to national standards developed in line with the European Union Directive on temperature and humidity, as well as lighting and size of animal cages (Anon 2010). After transportation to the Department vivarium, the animals were provided with a two-week adaptation period. In the room, apart from natural lighting, there was also artificial lighting in the form of glow discharge tubes. Exposure time of animals in artificial light was $5 \mathrm{~h}$ and the intensity was 40 lux. Temperature was optimal at $18-20^{\circ} \mathrm{C}$, and the relative humidity was $55-60 \%$. The animals were kept individually in metal cages designed for such animals, and were fed with full-portion rabbit feed, 0.15-0.20 $\mathrm{kg} / \mathrm{day}$, and had unlimited access to water. Blood for the tests was drawn (from four different groups of animals) through a port at $8.00 \mathrm{AM}$ from the auricular marginal vein in four seasons of the year (30 animal per season), in spring (May), summer (June), autumn (October), and winter (January) at $24 \mathrm{~h}$ intervals, for three consecutive days, at 0,24 and $48 \mathrm{~h}$ from commencement of the study.

The assessment of apoptosis of lymphocytes and granulocytes was performed using a FACScan flow cytometer by Becton Dickinson with FACSDiva software (USA), using an ApoFluor ${ }^{\circledR}$ Green Caspase the reagent kit (MP Biomedicals, USA) to detect the activity of the total caspase pool 1, 3, 4, 5, 6, 7, 8, 9 in granulocytes and lymphocytes of rabbit peripheral blood. The results are shown as percentage of apoptotic granulocytes and lymphocytes (Table 1 and 2). Heparinised blood was centrifuged for 5 minutes at $400 \mathrm{xg}$, after which $300 \mu \mathrm{l}$ of the suspension obtained was transferred to eppendorf test tubes and $10 \mu \mathrm{l}$ of ApoFluor ${ }^{\circledR}$ Green fluorescent colorant was added, mixed and incubated for 60 minutes at $37^{\circ} \mathrm{C}$ in the presence of $5 \% \mathrm{CO} 2$, mixing every 20 minutes. $2 \mathrm{ml}$ of rinsing buffer was then added to the mixture to remove excess colorant, after which it was centrifuged for 5 minutes at $400 \mathrm{xg}$.

After the extraction of supernatant, the centrifugation procedure was repeated, after which $400 \mu$ of rinsing buffer and $2 \mu \mathrm{l}$ of propidium iodide (PI) was added to the suspension of cells stained with ApoFluor ${ }^{\circledR}$ Green. The test tubes were then incubated in ice for 10 minutes and analysed using the flow cytometer. Two colorants - ApoFluor ${ }^{\circledR}$ Green and PI were used to differentiate between live (apoptotic) cells (green) and dead (necrotic) cells (red). Interpretation of the 
results was performed by calculating from the total pool of cells, the percentage of apoptotic granulocytes and lymphocytes, as the flow cytometer recorded both granulocytes and lymphocytes as Apo(+)PI(-) cells - stained with ApoFluor ${ }^{\circledR}$ Green, but not stained with propidium iodide, and Apo(+)PI (+) cells - stained both with ApoFluor ${ }^{\circledR}$ Green and PI, and these cells were treated as apoptotic (Niedźwiedzka-Rystwej and Deptuła 2012).

The results of the study are presented as average values and standard deviation in Tables 1 and 2 for each season, and were subjected to statistical analysis with the t'Student test at $\mathrm{p}=0.05$.

\section{Results}

Group I (Table 1) apoptosis values, expressed in absolute numbers, vary in particular seasons and, in the case of lymphocytes are the highest in winter and autumn (36.02\% and $31.24 \%$, respectively), and the lowest in spring and summer $(26.73 \%$ and $22.72 \%$, respectively); in the case of apoptotic granulocytes, the highest values were recorded in summer and spring $(14.69 \%$ and $12.95 \%$, respectively), and the lowest in winter and autumn $(8.16 \%$ and $8.57 \%$, respectively). Statistical analysis of such results (Table 1) showed that more changes are found in apoptosis values for granulocytes than for lymphocytes. Differences in the granulocyte apoptosis values between summer and autumn, and between summer and winter, as well as between summer and autumn, and between spring and winter were noted; changes to lymphocyte apoptosis values were only recorded between summer and winter, and between spring and winter, as well as summer and autumn. Therefore, it must be assumed that, in the animals studied, the season affects both the values for apoptosis of lymphocytes and granulocytes, although differently for particular seasons, and the changes are more intense in the case of values for granulocyte apoptosis than lymphocyte apoptosis.

Values for apoptosis of lymphocytes in Polish mixed-breed rabbits with addition of meat-breed rabbits (group II), expressed in absolute values (Table 2), vary in the four seasons, and in the case of lymphocytes were the highest in spring and winter (29.13\% and $28.86 \%$, respectively), and the lowest in summer and autumn $(25.43 \%$ and $26.04 \%$, respectively); while in the case of apoptotic granulocytes, the highest values were recorded in summer and spring (14.20\% and $11.15 \%$, respectively), and the lowest in autumn and winter ( $7.46 \%$ and $7.64 \%$, respectively). In contrast to mixed-breed rabbits (group I) (Table 1), statistical analysis of such values in group II animals
(Table 2) showed that statistically significant differences were only recorded for apoptosis values in granulocytes and, as compared to the changes in rabbits from group II, were less intensive, as they referred to the values between summer on the one hand and autumn and winter on the other, and between spring and autumn, and between spring and winter. Therefore, in group II rabbits the season has a less intense impact, and only affects granulocyte apoptosis values.

Irrespective of the type of mixed-breed rabbits, apoptosis values were higher for lymphocytes than for granulocytes. The season appears to affect, although differently, apoptosis values for lymphocytes and granulocytes in rabbits from group I and II, since in rabbits from group I, as compared to group II, apoptosis values for lymphocytes and granulocytes are less different, while in group I rabbits more statistically significant changes to the apoptosis values of granulocytes were recorded than for lymphocytes since in group II animals such changes only referred to granulocytes.

\section{Discussion}

The apoptosis values of peripheral blood lymphocytes and granulocytes in investigated rabbits from groups I and II obtained in the present study can be compared to previously obtained results for mixed-breed rabbits (Jacobson et al. 1978, Nowczyk et al. 2005, Cetin et al. 2009, Niedźwiedzka-Rystwej et al. 2014, Tokarz-Deptuła et al. 2014, Tokarz-Deptuła et al. 2014a), where the impact of the season on the quantity of peripheral blood lymphocytes and granulocytes was assessed. The present results for apoptosis can also be compared to the seasonal affect on factors of immunological activity of such blood cells (Nowaczyk et al. 2005, Hukowska-Szematowicz et al. 2015, Tokarz-Deptuła et al. 2015).

Assessment of the recorded impact of the seasons on the values for apoptosis of lymphocytes in Polish mixed-breed rabbits (group I) (Table 1) and Polish mixed-breed rabbits with the addition of meat-breed rabbits (group II) (Table 2), expressed in absolute values, indicates the highest values were in winter and autumn, and the lowest in summer and spring. In group II, however, the highest values were observed in spring, and the lowest in summer. These results are partly confirmed by studies on the impact of the season on the activity of peripheral blood lymphocytes measured with the synthesis of serum immunoglobulins G (IgG) (Nowczyk et al. 2005, Hukowska-Szematowicz et al. 2015, Tokarz-Deptuła et al. 2015) and total volume of Ig expressed in ZST units (Nowaczyk et al. 2005, Hukowska-Szematowicz 
2015, Tokarz-Deptuła et al. 2015), where the highest values were recorded in spring and in summer. The impact of the season on the apoptosis values of granulocytes in both groups, where the highest values were reported in summer and spring, and the lowest in autumn and winter, is also confirmed by the results obtained by Nowaczyk et al. (2005), which showed that the activity of peripheral blood granulocytes measured using adherence capacity depended on the season, since higher values of this factor were recorded in spring, as compared to summer and winter, and in summer as compared to winter. The impact of the season on lymphocytes and granulocytes, investigated through apoptosis and expressed with the quantity of such cells, is also confirmed by the results related to the impact of the season on the volume of lymphocytes, neutrophil, acidophil, and basophil granulocytes, and monocytes in peripheral blood (Jacobson et al. 1978, Nowaczyk et al. 2005, Cetin et al. 2009, Niedźwiedzka-Rystwej et al. 2014, Tokarz-Deptuła et al. 2014, Tokarz-Deptuła et al. 2014a), because their volume in peripheral blood is conditioned by apoptosis. The impact of the season on immunological activity, determined with the apoptosis of lymphocytes and granulocytes of rabbit blood is evidenced by studies in humans (Dopico et al. 2015), which showed the impact of the seasons on the expression of genes conditioning the synthesis of IL-6 and CRP, since greater synthesis of such substances was found in the autumn and winter period as compared to the spring and summer period; this study is convincing, as to the impact of the seasons on immunity since it indicates that periodicity related to the seasons affects the macro-organisms at the genes level. Such observations were also confirmed by Bell-Pedersen (2000), whose study showed that the periodicity clock in organisms is frequent and operates at all levels of physiological processes in cells and tissues, while recently it has been proven that it is also associated with haematopoiesis (Casanova-Acebes 2013).

\section{Conclusion}

The values for apoptosis of peripheral blood lymphocytes and granulocytes in mixed-breed rabbits from groups I and II are higher for lymphocytes than for granulocytes, and depend (although differently) on the season of the year. In rabbits from group I, as compared to rabbits from group II, the season of the year more intensively affects the values for apoptosis of lymphocytes and granulocytes, and, in animals from group I, it was recorded that statistical differences in the apoptosis values refer to both lymphocytes and granulocytes, while in rabbits from group II they refer only to the values for granulocytes.

It was shown that, in rabbits from group I, the values for apoptosis of lymphocytes were the highest in winter and autumn $(36.02 \%$ and $31.24 \%$, respectively), and the lowest in spring and summer $(26.73 \%$ and $22,72 \%$, respectively), whereas in the case of granulocytes the highest values were in summer and spring (14.69\% and $12.95 \%$, respectively), and the lowest in winter and autumn $(8.16 \%$ and $8.57 \%$, respectively). In mixed-breed rabbits with the addition of meat-breed blood (group II), the values for apoptosis of lymphocytes were the highest in spring $(29.13 \%)$, and the lowest in summer $(25.43 \%)$; whereas in the case of granulocytes the highest values were in summer and spring $(14.0 \%$ and $11.15 \%$, respectively), and the lowest in autumn and winter (7.46\% and $7.64 \%$, respectively).

\section{References}

Alonso C, Oviedo JM, Martin-Alonso JM, Diaz E, Boga JA, Parra F (1998) Programmed cell death in the pathogenesis of rabbit hemorrhagic disease. Arch Virol 143: 321-332.

Anon (1987) Information and training materials of the Laboratory Animals Section, General Assembly of the Association of Agriculture Engineers and Technicians, In: Materiały informacyjno-szkoleniowe Sekcji ds. Zwierząt Laboratoryjnych ZG Stowarzyszenia Inżynierów i Techników Rolnictwa, Warszawa, pp. 26-77.

Anon (2010) Directive 2010/63/EC of the European Parliament and the Council of 22 September 2010 on the protection of animals used for scientific purposes (European Union Official Journal L267/33).

Baś M, Cywińska A, Sokołowska J, Krzyżowska (2004) Apoptosis - programmed cell death. Part III. The role of apoptosis in physiology and pathology. Życie Wet 79: 671-675.

Bell-Pedersen D (2000) Understanding circadian rhythmicity in Neurospora crassa: from behavior to genes and back again. Fungal Genet Biol 29: 1-18.

Bell-Pedersen D, Cassone VM, Earnest DJ, Golden SS, Hardin PE, Thomas TL, Zoran MJ (2005) Circadian rhythms from multiple oscillators: lessons from diverse organisms. Nat Rev Genet 6: 544-556.

Casanova-Acebes M, Pitaval C, Weiss LA, Nombela-Arrieta C, Chevre R, Gonzalez AN, Kunisaki Y, Zhang D, van Rooijen N, Silberstein LE, Weber C, Nagasawa T, Frenette PS, Castrillo A, Hidalgo A (2013) Rhythmic modulation of the hematopoietic niche through neutrophil clearance. Cell 153: 1025-1035.

Cetin N, Bekyurek T, Cetin E (2009) Effect of sex, pregnancy and season on some hematological and biochemical blood values in angora rabbits. Scand J Lab Anim Sci 36: $155-162$.

De Jong S, Neeleman M, Luykx JJ, ten Berg MJ, Strengman E, Den Breeijen HH, Stijvers LC, Buizer-Voskamp JE, Bakker SC, Kahn RS, Horvath S, Van Solinge WW, Ophoff RA (2014) Seasonal changes in gene expression 
represent cell-type composition in whole blood. Hum Mol Genet 23: 2721-2728.

Deptuła W, Dorynek Z (1993) The levels of haematologic and biochemical indices in dairy cows in yearly cycle. Annals of the Agricultural Academy of Poznan 246: 15-21.

Deptuła W, Smolik M, Smolik B, Belina G, Szenfeld J, Tokarz B, Szudej T (1992) The results of haematological-immunological studies in cattle kept in barns industrial. Przegląd Hodowlany 5: 15-18.

Dopico XC, Evangelou M, Ferreira RC, Guo H, Pekalski ML, Smyth DJ, Cooper N, Burren OS, Fulford AJ, Henning BJ, Prentice AM, Ziegler AG, Bonifacio E, Wallace C, Todd JA (2015) Widespread seasonal gene expression reveals annual differences in human immunity and physiology. Nat Commun 6: 7000.

Elmore S (2007) Apoptosis: a review of programmed cell death. Toxicol Pathol 35: 495-516.

Fadeel B, Orrenius S, Zhivotovsky B (1999) Apoptosis in human disease: a new skin for the old ceremony? Biochem Biophys Res Commun 266: 699-717.

Gamble KL, Berry R, Frank SJ, Young ME (2014) Circadian clock control of endocrine factors. Nat Rev Endocrinol 10: 466-475.

Hukowska-Szematowicz B (2013) Genetic and immunological characteristics of European strains of RHD (Rabbit Haemorrhagic Disease) virus. Pol J Environ Stud 2: $1-114$.

Hukowska-Szematowicz B, Tokarz-Deptuła B, Niedźwiedzka-Rystwej P, Adamiak M, Trzeciak-Ryczek A, Deptuła W (2015) Leukocyte intacellular kiling test and selected serum proteins in Polish mixed-breed rabbits. Med Weter 71: 763-768.

Husakova T, Pavlata L, Pechova A, Tichy L, Hauptmanova $\mathrm{K}$ (2015) The influence of sex, age and season on the haematological profile of alpacas (Vicugna pacos) in Central Europe. Vet Med- Czech 60: 407-414.

Jacobson HA, Kirkpatrick RL, Burkhart HE, Davis JW (1978) Hematologic comparisons of shot and live trapped cottontail rabbits. J Wildl Dis 14: 82-88.

Niedźwiedzka-Rystwej P, Deptuła W (2012) Apoptosis of peripheral blood leukocytes from rabbits infected with non-haemagglutinating strains of rabbit haemorrhagic disease virus (RHDV). Vet Immunol Immunopathol 149: 54-57.

Niedźwiedzka-Rystwej P, Deptuła W (2012a) Lymphocyte subpopulations and apoptosis of immune cells in rabbits experimentally infected with a strain the RHD virus having a variable haemagglutination capacity. Pol J Vet Sci 15: 43-49.

Niedźwiedzka-Rystwej P, Hukowska-Szematowicz B, Tokarz-Deptuła B, Trzeciak-Ryczek A, Działo J, Deptuła W (2013) Apoptosis of peripheral blood leukocytes in rabbits infected with different strains of rabbit haemorrhagic disease virus. Acta Biochim Pol 60: $65-69$.

Niedźwiedzka-Rystwej P, Tokarz-Deptuła B, Deptuła W (2013a) Apoptosis of granulocytes and lymphocytes in peripheral blood in rabbits infected with haemagglutinating and non-haemagglutinating antigenic variants of the RHD (rabbit haemorrhagic disease) virus. Pol J Vet Sci 16: 223-229.

Nowaczyk P, Deptuła W, Tokarz-Deptuła B (2005) Selected indicators of blood in rabbits in annual cycle. Acta Biologica 12: 57-63.

O’Brien V (1998) Viruses and apoptosis. J Gen Virol 79: 1833-1845.

Pyza E, Nowak JZ (1999) Molecular mechanisms of the biological clock. Post Hig Med Dośw 53: 423-444.

Solary E, Dubrez L, Eymin B (1996) The role of apoptosis in the pathogenesis and treatment of diseases. Eur Respir J 9: 1293-1305.

Stark MA, Huo Y, Burcin TL, Morris MA, Olson TS, Ley K (2005) Phagocytosis of apoptotic neutrophils regulates granulopoiesis via IL-23 and IL-17. Immunity 22: 285-294.

Takahashi JS, Hong HK, Ko CH, McDearmon EL (2008) The genetics of mammalian circadian order and disorder: implications for physiology and disease. Nat Rev Genet 9: 764-775.

Tokarz-Deptuła B, Niedźwiedzka-Rystwej P, Adamiak M, Hukowska-Szematowicz B, Trzeciak-Ryczek A, Deptuła $\mathrm{W}$ (2014) Values of white and red blood cell parameters in Polish mixed breed rabbits in the annual cycle. Pol J Vet Sci 17: 643-655.

Tokarz-Deptuła B, Niedźwiedzka-Rystwej P, Hukowska-Szematowicz B, Adamiak M, Trzeciak-Ryczek A, Deptuła W (2014) B-cell and T-cell in peripheral blood in Polish mixed breed rabbits with addition of blood of meet breeds. Pol J Vet Sci 17: 421-426.

Tokarz-Deptuła B, Niedźwiedzka-Rystwej P, Hukowska-Szematowicz B, Trzeciak-Ryczek A, Adamiak M, Deptuła W (2014a) B and T cell values in peripheral blood in Polish mixed breed rabbits. Centr Eur J Immunol 39: $1-5$.

Tokarz-Deptuła B, Niedźwiedzka-Rystwej P, Adamiak M, Hukowska-Szematowicz B, Trzeciak-Ryczek A, Deptuła W (2015) Natural immunity factors in Polish mixed breed rabbits. Pol J Vet Sci 18: 19-28.

Weinmann P, Scharffetter-Kochanek K, Forlow SB, Peters T, Walzog B (2003) A role of apoptosis in the control of neutrophil homeostasis in the circulation: insights from CD18-deficient mice. Blood 101: 739-746.

Zapata B, Fuentes V, Bonacic C, Gonzalez B, Villouta G, Bas F (2003) Haematological and clinical biochemistry findings in capative juvenile guanacos (Lama guanicoe Muller 1776) in central Chile. Small Ruminant Res 48: $15-21$. 